\title{
Screening sorghum genotypes for salinity tolerant biomass production
}

\author{
L. Krishnamurthy • Rachid Serraj • \\ C. Tom Hash · Abdullah J. Dakheel • \\ Belum V. S. Reddy
}

Received: 11 November 2006/ Accepted: 18 December 2006/Published online: 10 January 2007

(C) Springer Science+Business Media B.V. 2007

\begin{abstract}
Genetic improvement of salt tolerance is of high importance due to the extent and the constant increase in salt affected areas. Sorghum [Sorghum bicolor (L.) Moench] has been considered relatively more salt tolerant than maize and has the potential as a grain and fodder crop for salt affected areas. One hundred sorghum genotypes were screened for salinity tolerance in pots containing Alfisol and initially irrigated with a $250-\mathrm{mM} \mathrm{NaCl}$ solution in a randomized block design with three replications. Subsequently 46 selected genotypes were assessed in a second trial to confirm their responses to salinity. Substantial variation in shoot biomass ratio was identified among the genotypes. The performance of genotypes was consistent across experiments. Seven salinity tolerant and ten salinity sensitive geno-
\end{abstract}

L. Krishnamurthy $(\bowtie) \cdot$ C. T. Hash .

B. V. S. Reddy

International Crops Research Institute for the

Semi-Arid Tropics (ICRISAT), Patancheru 502 324,

Andhra Pradesh, India

e-mail: L.Krishnamurthy@cgiar.org

R. Serraj

CSWS, International Rice Research Institute (IRRI),

DAPO Box 7777, Metro, Manila, Philippines

\section{A. J. Dakheel}

International Center for Biosaline Agriculture (ICBA), P.O. Box 14660, Dubai, United Arab

Emirates types are reported. Relative shoot lengths of seedlings were genetically correlated to the shoot biomass ratios at all stages of sampling though the relationships were not close enough to use the trait as a selection criterion. In general, the whole-plant tolerance to salinity resulted in reduced shoot $\mathrm{Na}^{+}$concentration. The $\mathrm{K}^{+} / \mathrm{Na}^{+}$ and $\mathrm{Ca}^{2+} / \mathrm{Na}^{+}$ratios were also positively related to tolerance but with a lesser $r^{2}$. Therefore, it is concluded that genotypic diversity exists for salt tolerance biomass production and that $\mathrm{Na}^{+}$exclusion from the shoot may be a major mechanism involved in that tolerance.

Keywords Salinity tolerance $\cdot$ Sorghum bicolor . Total biomass $\cdot$ Ionic distribution $\cdot$ Shoot $\mathrm{Na}^{+}$ content $\cdot \mathrm{K}^{+} / \mathrm{Na}^{+}$ratio

\section{Introduction}

Salinization is the increase in concentration of total dissolved solids in the soil. Saline soils are estimated to cover about $5-10 \%$ of the world's arable land (Szabolcs 1994; Tanji 1990), and the area affected by salinity is increasing steadily, in part due largely to mismanaged irrigation (Ghassemi et al. 1995; Iyengar and Reddy 1994). Soil salinity drastically reduces the productivity of most crops although to a varying extent across species (Francois and Maas 1994; Munns et al. 
2002). Besides improving water management practices to reduce the salt accumulation in the root zone, there is a need to improve salinity tolerance of important crops.

Sorghum [Sorghum bicolor (L.) Moench], a major grain and forage crop, was previously characterized as moderately tolerant to salinity (Maas 1985; Igartua et al. 1995). It is considered relatively more salt tolerant than maize, the cereal crop ranking first in productivity globally (Maas 1985), and so sorghum has the potential as a crop for salt affected areas (Ayers and Westcott 1985; Igartua et al. 1994). The presence of large genotypic variation for tolerance to salinity reported in sorghum (Taylor et al. 1975; Hassanein 1985; Azhar and McNeilly 1987, 1988; Maiti et al. 1994) offers a good scope for integrating tolerance characteristics into appropriate breeding programs to improve crop productivity on saline soils.

Several workers have shown that plant tolerance to high concentrations of salt (salinity) in their rooting medium is under genetic control (Epstein and Jeffries 1964; Epstein 1985; Epstein and Rains 1987; McNeilly 1990; Shannon 1990; Munns et al. 2000). Both additive and dominance effects appear to influence salinity tolerance measured as relative root length (RRL) in sorghum (Azhar and McNeilly 1988) and $\mathrm{Na} / \mathrm{K}$ ratio in rice (Gregorio and Senadhira 1993) and the heritability values were reported to be low. In fact, QTLs for salt tolerance have been described in several cereals including rice (Flowers et al. 2000; Koyama et al. 2001), barley (Ellis et al. 1997; Mano and Takeda 1997) and bread wheat (Munns et al. 2000; Semikhodiskii et al. 1997) although markers were not robust enough to be used across a range of germplasm. However, the limited success of previous studies was also related to the limited diversity available within the modern cultivars that were used as parents (Munns et al. 2002).

Efforts to enhance crop yields under salinity stress have also had a limited success because available knowledge of the mechanisms of salt tolerance has not been turned into useful selection criteria to evaluate a wide range of genotypes within and across species. Attempts have been made to evaluate salt tolerance at germination and emergence stages in grain sorghum (Igartua et al. 1994), and large genotypic differences were reported, but this early evaluation appears to have little relation with overall performance under saline conditions (Munns et al. 2002). Though $\mathrm{Na}^{+}$exclusion and grain $\mathrm{K}^{+} / \mathrm{Na}^{+}$ratios have been suggested to be reliable traits for selecting salt tolerant crops (Munns and James 2003; Munns et al. 2002; Poustini and Siosemardeh 2004; Netondo et al. 2004), the value of that trait has not been used in a large scale. Therefore, there is a need to identify traits associated with salinity tolerance, and simple, high throughput, repeatable screening methods to evaluate large number of genotypes. In fact, the variation in whole-plant biomass responses to salinity was considered to provide the best means of initial selection of salinity tolerant genotypes (Shannon 1984; Ashraf and McNeilly 1987), prior to the evaluation on the basis of specific traits.

In the present study, we first evaluated the genotypic variation for salinity tolerance during the early vegetative stage among a variety of sorghum entries, including currently used breeding lines, based on the proportion of shoot biomass production under saline condition as that of non-saline control in the first 35 days. Then, we investigated possible physiological traits that could be used later on as screening criteria. We also evaluated seed germination and seedling growth as possible indicators of salinity tolerance, and compared these responses to whole-plant reaction to salinity close to anthesis.

\section{Materials and methods}

Pot culture screening

In the first pot experiment, 100 entries of sorghum comprising large number of hybrid parents (for grain and forage values) popular and improved varieties, populations and two hybrids hereafter called genotypes, were exposed to $\mathrm{NaCl}$ salinity using a randomized block design. Pots of $12.5 \mathrm{~cm}$ diameter were filled with $1.2 \mathrm{~kg}$ of Alfisol mixed with di-ammonium phosphate at the equivalent rate of $200 \mathrm{~kg} \mathrm{ha}^{-1}$ on 29 March 2003, and sealed at the bottom, to avoid salt loss. Two levels of 
salinity were applied prior to sowing through a one-time application of deionized water with and without $250 \mathrm{mM} \mathrm{NaCl}$. The amount of water added to bring the soil to field capacity was determined on a soil weight basis $(23.2 \%$, w/w) The resulting solution electrical conductivity (EC) was $23.4 \mathrm{dS} \mathrm{m}^{-1}$ and the $\mathrm{NaCl}$ treated soil ECe was $18.1 \pm 0.19 \mathrm{dS} \mathrm{m}^{-1}$, compared to $2.9 \pm 0.26$ without $\mathrm{NaCl}$. Irrigation was provided on alternate days up to 20 days after sowing (DAS) and every day at later stages of growth to replace evapotranspirational losses and bring soil moisture levels to field capacity. The water needed for these subsequent irrigations was determined by daily weighing of ten representative pots, to avoid water logging or deficit in the pots. Sixteen seeds of each genotype were sown in each pot in four equally spaced hills. A maximum of four plants per pot were retained after thinning at 10 DAS. One plant per pot was sampled at 18, 25, 32 and 39 DAS. In case a pot had less than four plants, the plants were reserved for the later sampling stage(s), and earlier sampling was skipped. The harvested plants were separated into root (extractable) and shoot, dried in hot air draught oven at $60^{\circ} \mathrm{C}$ for 3 days and the dry weights were recorded. A ratio of shoot biomass measured under salinity to that of control was calculated replicate-wise for each sample and these ratios were subjected to statistical analysis. This ratio was used as a proxy for estimating the salinity tolerance for biomass production at vegetative stage.

A second pot experiment was conducted with 43 genotypes, including 40 tolerant and 3 sensitive genotypes selected from the first experiment. Experiment 2 was sown on 17 September 2003. The experimental procedure was the same as in experiment 1 , except that the pot size was $15 \mathrm{~cm}$ diameter and contained $2 \mathrm{~kg}$ Alfisol, and that all plants were harvested at the same time at 35 DAS.

Soil and plant assessment

Ionic contents were estimated using the sample harvested at 39 DAS from experiment 1. The pooled shoots (stem + leaves) of all the three replications were used for the determination of $\mathrm{N}$,
$\mathrm{P}, \mathrm{K}, \mathrm{Na}$ and $\mathrm{Ca}$. One hundred and fifty milligrams of finely ground shoot sample was digested in $4 \mathrm{ml}$ of concentrated sulfuric acid with $0.5 \%$ selenium powder at $360^{\circ} \mathrm{C}$ for $75 \mathrm{~min}$ on a block digester and the digest was diluted to $75 \mathrm{ml}$. Using this digest, total $\mathrm{N}$ was estimated using SKALAR Auto Analyser, the Netherlands (Krom 1980) to determine whether $\mathrm{N}$ absorption has any role in reducing plant growth under saline conditions. Exchangeable $\mathrm{K}, \mathrm{Na}$ and $\mathrm{Ca}$ were estimated (Sahrawat et al. 2002) using an atomic absorption spectrophotometer (Varion model 1200, Australia).

The EC of the $\mathrm{NaCl}$ solutions was measured directly using a conductivity meter (Model 148150, Cole-Parmer Instrument Company, Chicago). The soil EC was measured using a 1:2 (soil:water, w/v) extract.

\section{Germination studies}

The germination of all 100 genotypes included in the first pot experiment was investigated in presence and absence of salinity. Twenty seeds of each genotype were surface sterilized with $1 \%$ sodium hypochlorite solution for $10 \mathrm{~min}$, and germinated on filter paper in closed Petri dishes for 6 days in $15 \mathrm{ml}$ deionized water (control) or in $15 \mathrm{ml}$ of a $250-\mathrm{mM} \mathrm{NaCl}$ solution in a randomized block design with three replications in a growth chamber at $28 / 25^{\circ} \mathrm{C}$ day/night temperature with $12 \mathrm{~h}$ light. Five representative seedlings from each Petri dish were used for the measurement of root and shoot length. Relative seed germination (RSG) was calculated as the ratio of the number of seeds germinated under saline conditions to the mean number of those germinated in control, RRL as the ratio of root length under saline conditions to the mean RL of control and relative shoot length (RSL) as the ratio of shoot length under saline conditions to the mean SL of control. These variables were subjected to statistical analysis and the best linear unbiased predictors for each trait were estimated. Correlations and regressions of RSG, RRL and RSL against the shoot biomass ratio observed under different stages of vegetative growth were performed on the best linear unbiased predictors. 
Statistical analysis

The data from any individual experiment were analyzed using the following linear additive mixed effects model

$Y_{\mathrm{ik}}=\mu+r+g_{\mathrm{k}}+e_{\mathrm{ik}}$

where $y_{\mathrm{ik}}$ is the observation recorded on genotype $\mathrm{k}$ in replicate $\mathrm{i}, \mu$ is the general mean, $r_{\mathrm{i}}$ is the effect of replicate $i, g_{k}$ is the effect of genotype $k$ and $e_{\mathrm{ik}}$ is the effect of the error term. The general mean $\mu$ and replicate effect $r_{\mathrm{i}}$ were considered as fixed effects. The genotype effect $g_{\mathrm{k}}$ and the error term $e_{\mathrm{ik}}$, were assumed as random effects each with mean 0 and constant variances $\sigma_{\mathrm{g}}^{2}$ and $\sigma_{\mathrm{e}}^{2}$, respectively. Using the above model, the statistical procedure of residual maximum likelihood was employed to obtain the unbiased estimates of the variance components $\sigma_{\mathrm{g}}^{2}$ and $\sigma_{\mathrm{e}}^{2}$, and the best linear unbiased predictions (BLUPs) of the performance of the 100 genotypes in the first and 43 genotypes in the second experiment. Heritability was estimated as $h^{2}=\sigma_{\mathrm{g}}^{2} /\left(\sigma_{\mathrm{g}}^{2}+\sigma_{\mathrm{e}}^{2}\right)$. The significance of genetic variability among genotypes was assessed from the standard error of the estimate of genetic variance $\sigma_{\mathrm{g}}^{2}$, assuming the ratio $\sigma^{2}{ }_{\mathrm{g}} / \mathrm{SE}\left(\sigma_{\mathrm{g}}^{2}\right)$ to follow normal distribution asymptotically.

The above model was extended for overexperiment analysis of the ratios of 43 genotypes that were common in both experiments, assuming experiment effect as fixed, with genotype $\times$ environment interaction (GEI) effect being a random effect assumed to have a mean

Table 1 Trial means, range of best linear unbiased predicted means and analysis of variance for shoot biomass ratio (shoot biomass under salinity/shoot biomass under of 0 and constant variance $\sigma_{\mathrm{gE}}^{2}$. The significance of GEI was assessed in a manner similar to that of $\sigma_{\mathrm{g}}^{2}$. The significance of the fixed effect of the year was assessed using the Wald statistic that asymptotically follows a $\chi^{2}$ distribution and is akin to the $F$-test in the traditional ANOVA.

One geometric mean ( $n$th root of the product of $n$ observations) of the shoot biomass ratios was calculated out of the four sample BLUPs for each genotype for the first experiment. This geometric mean of the shoot biomass ratio and the shoot biomass ratio of the second experiment were used for grouping the 43 genotypes into representative groups by a hierarchical cluster analysis (using Ward's ISS method). All the statistical analyses were carried out using Genstat, Release 6.1 (Payne 2002).

\section{Results}

Pot culture screening

The genotypic variability for salinity tolerance was assessed in the current study, based on the ratio of shoot (stem + leaf) biomass produced under salinity as that of control. Large genotypic variation was found for the shoot biomass ratio at all stages of crop growth in experiment 1 and at 35 DAS in experiment 2 (Table 1). The heritability values observed for the four samples ranged from 0.36 to 0.46 and there was a trend of increase in these values with increasing age of the plants sampled.

control) for sorghum genotypes sampled at 18, 25, 32 and 39 days after sowing (DAS) in experiment 1 and shoot biomass ratio at $35 \mathrm{DAS}$ in experiment 2

\begin{tabular}{|c|c|c|c|c|}
\hline Trait & Trial mean & $\begin{array}{l}\text { Range of } \\
\text { predicted means }\end{array}$ & $\sigma_{\mathrm{g}}^{2}(\mathrm{SE})$ & Heritability $\left(h^{2}\right)$ \\
\hline \multicolumn{5}{|c|}{ Ratio of shoot biomass } \\
\hline \multicolumn{5}{|c|}{ Experiment $1(n=100)$} \\
\hline $18 \mathrm{DAS}$ & 0.247 & $0.091-0.450$ & $0.0111(0.0026)$ & 0.36 \\
\hline 25 DAS & 0.314 & $0.100-0.569$ & $0.0155(0.0034)$ & 0.42 \\
\hline 32 DAS & 0.323 & $0.090-0.706$ & $0.0194(0.0039)$ & 0.46 \\
\hline 39 DAS & 0.620 & $0.302-1.000$ & $0.0317(0.0072)$ & 0.38 \\
\hline \multicolumn{5}{|c|}{ Experiment $2(n=43)$} \\
\hline $35 \mathrm{DAS}$ & 0.090 & $0.036-0.147$ & $0.0011(0.0004)$ & 0.36 \\
\hline
\end{tabular}


The hierarchical cluster analysis had yielded five distinct groups at a similarity index of 0.90 and the genotypes in groups with the highest and the lowest shoot biomass ratios were presented in Table 2.

\section{Ion distribution}

Shoot $\mathrm{Na}^{+}$content under saline conditions was negatively related to the shoot biomass ratio (Fig. 1a; $r^{2}=0.29, p \leq 0.001$ ). This relationship improved further with the mean shoot biomass observed under salinity (Fig. 1b; $r^{2}=0.42$, $p \leq 0.001)$. Shoot $\mathrm{Na}^{+}$content under control did not show any such relationship either with the shoot biomass ratio or actual shoot biomass under control (data not shown). The overall average shoot $\mathrm{Na}^{+}$content under salinity $(0.51 \%)$ was about two times higher than that under control conditions $(0.29 \%)$ and ranged from 0.26 to $0.92 \%$.

Shoot $\mathrm{K}^{+}$content under saline conditions was not significantly related to the shoot biomass ratio

Table 2 The shoot biomass ratio of sorghum genotypes that clustered under tolerant and sensitive groups based on hierarchical cluster analysis (Ward's ISS method) using the data of experiment 1 (geometric mean of 18, 25, 32 and 39 day ratios) and the 35 day ratio of experiment 2

\begin{tabular}{lll}
\hline Genotype & \multicolumn{2}{l}{ Mean shoot biomass ratio } \\
\cline { 2 - 3 } & Experiment 1 & Experiment 2 \\
\hline Highly tolerant & & \\
CSV 15 & 0.539 & 0.098 \\
ICSB 766 & 0.518 & 0.087 \\
NTJ 2 & 0.505 & 0.109 \\
ICSV 95030 & 0.536 & 0.106 \\
S 35 & 0.524 & 0.147 \\
ICSB 589 & 0.501 & 0.125 \\
ICSB 676 & 0.502 & 0.116 \\
Highly sensitive & & \\
GD 65008 Brown & 0.352 & 0.077 \\
ICSB 700 & 0.356 & 0.079 \\
PSH 1 & 0.348 & 0.082 \\
ICSB 699 & 0.361 & 0.072 \\
ICSR 93024-2 & 0.317 & 0.086 \\
ICSV 96020 & 0.337 & 0.070 \\
ICSV 90017 & 0.320 & 0.088 \\
ICSB 405 & 0.327 & 0.082 \\
ICSR 170 & 0.331 & 0.038 \\
ICSR 56 & 0.330 & 0.047 \\
\hline
\end{tabular}
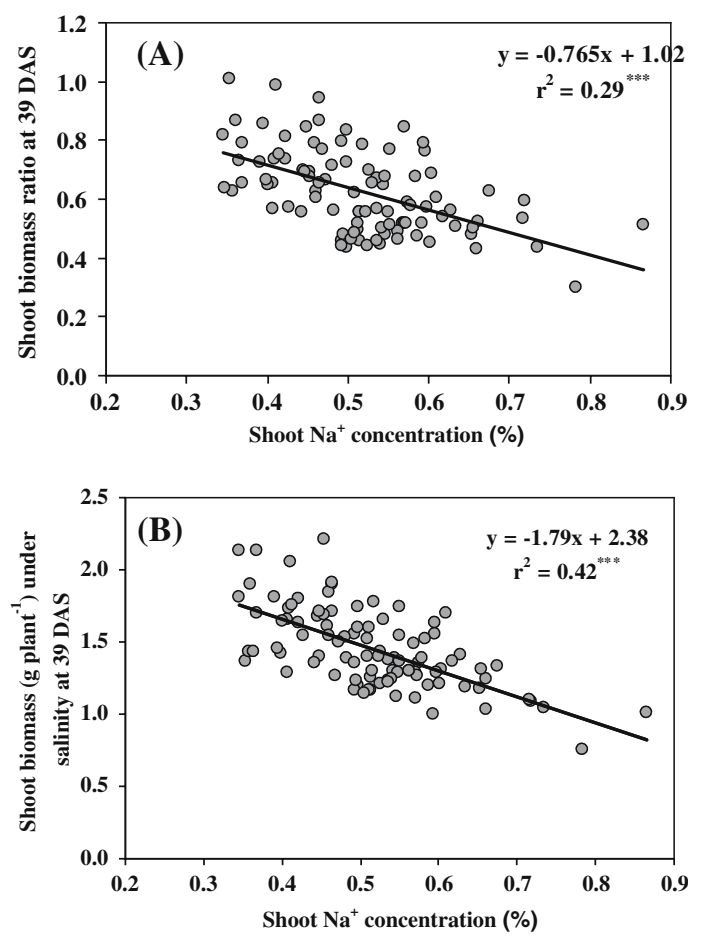

Fig. 1 Relationship of shoot $\mathrm{Na}^{+}$concentration (\%) with (a) shoot biomass ratio at 39 DAS and (b) shoot biomass under salinity at 39 DAS (triple asterisks significant at 0.001 )

$\left(r^{2}=0.03\right)$ whereas it was positively related with the shoot biomass under salinity $\left(r^{2}=0.13\right.$, $p \leq 0.001$ ) (data not shown). Unlike the $\mathrm{Na}^{+}$ content, the mean change in overall mean $\mathrm{K}^{+}$ content under salinity $(1.13 \%)$ was not that different from that of the one under control $(0.98 \%)$. The $\mathrm{K}^{+} / \mathrm{Na}^{+}$ratio was significantly and positively associated with the shoot biomass ratio at 39 DAS ( $p \leq 0.001$; Fig. 2a). Also this relationship was much closer with the shoot biomass under salinity $\left(r^{2}=0.31, p \leq 0.001\right)$ (data not shown). The overall mean of $\mathrm{K}^{+} / \mathrm{Na}^{+}$ratio was about 2.4 under saline conditions, substantially lower than that under the non-saline control (about 3.5).

$\mathrm{Ca}^{2+}$ content was not significantly correlated either to the shoot biomass ratio or to the shoot biomass under salinity. In contrast, the $\mathrm{Ca}^{2+} / \mathrm{Na}^{+}$ ratio was positively related to both shoot biomass ratio $\left(r^{2}=0.16, p<0.001\right.$; Fig. $\left.2 b\right)$ as well as the shoot biomass under salinity $\left(r^{2}=0.33\right.$, $p<0.001)$. 

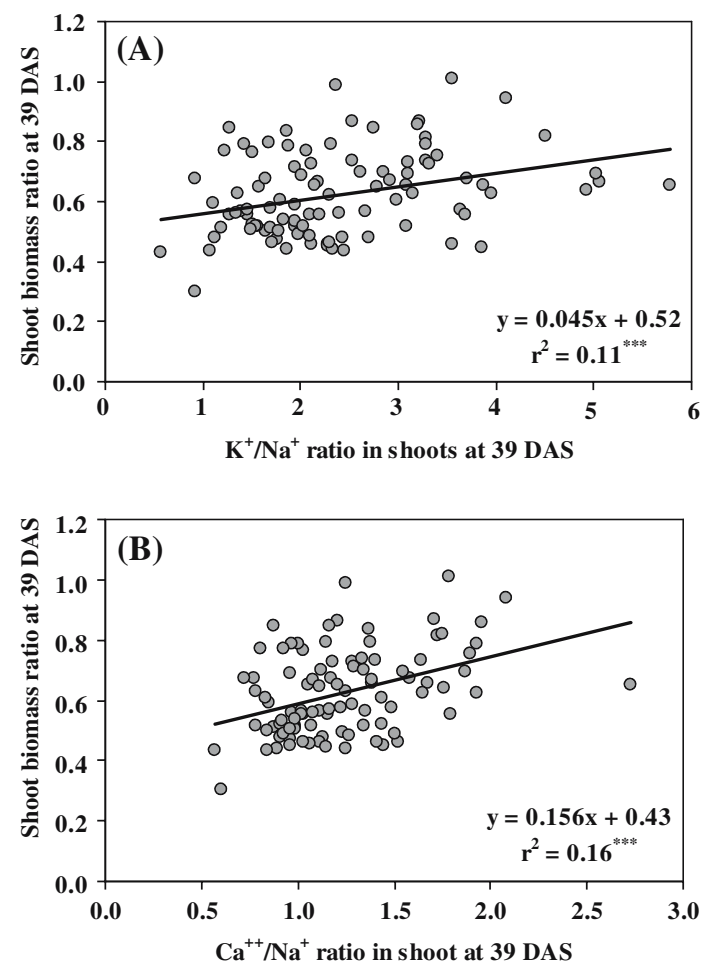

Fig. 2 Relationship between the (a) shoot $\mathrm{K}^{+} / \mathrm{Na}^{+}$ratio and the shoot biomass ratio at 39 DAS and (b) shoot $\mathrm{Ca}^{2+} /$ $\mathrm{Na}^{+}$ratio and the shoot biomass ratio at 39 DAS (triple asterisks significant at 0.001)

Under saline conditions, the $\mathrm{N}$ concentration of shoots was negatively correlated with the shoot biomass ratio $\left(r^{2}=0.29, p \leq 0.001\right.$; Fig. 3$)$ as well as the shoot biomass under salinity $\left(r^{2}=0.48, \quad p \leq 0.001\right)$ whereas under control

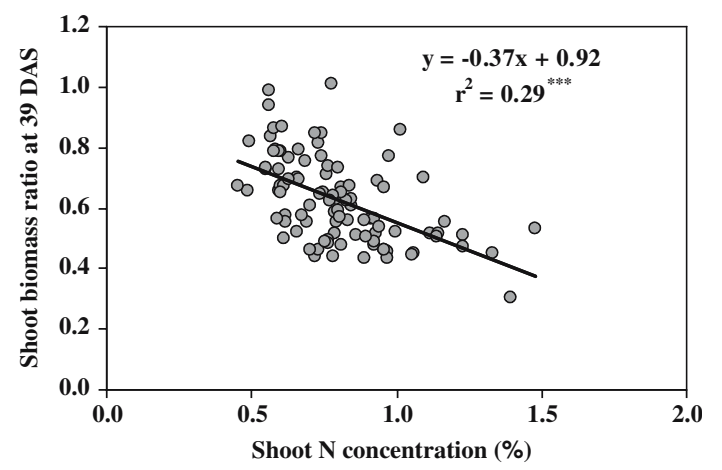

Fig. 3 Relationship of shoot $\mathrm{N}$ concentration (\%) with the shoot biomass ratio at 39 DAS under saline conditions conditions this correlation was not significant. This result also indicated that the salinity tolerant genotypes had relatively lower $\mathrm{N}$ concentration, varying from 0.5 to $0.9 \%$ (Fig. 3). This was likely due to the fact that tolerant plants maintained relatively higher growth rates and thus "diluting" the amount of $\mathrm{N}$ taken up, while reduced growth in sensitive genotypes resulted in higher $\mathrm{N}$ concentrations in the shoot. In general, $\mathrm{N}$ acquisition by plants seems to have been affected under salinity, as indicated by the overall environmental means. The overall mean $\mathrm{N}$ concentration under saline conditions was $0.80 \%$, compared to $0.95 \%$ in the non-saline control.

\section{Germination studies}

Sixteen genotypes that showed $<80 \%$ germination under control conditions were excluded from the study of the variation in seed germination under salinity and a subsequent relationship between root and shoot growth under salinity at seedling stage with the biomass production at 39 DAS, to avoid confusion between poor seed germination and salt effects on early vegetative growth. There was a significant genotypic variation in the response of germination to salinity measured as the variation in the ratio of germination under salinity to that of control (RSG) (Table 3). However, germination was relatively less affected by salinity as shown by the trial mean for RSG (Table 3). RSG was $30-40 \%$ in genotypes ICSR 170, ICSR 56 and M 35-1 indicating that these genotypes are highly sensitive to seed

Table 3 Trial means, range of best linear unbiased predicted means and analysis of variance for the ratio of seeds germinated in $250 \mathrm{mM}$ saline solution as that of control (\%) (RSG), ratio of root length under salinity as that of control (RRL) and the ratio of shoot length under salinity as that of control (RSL) in 84 sorghum genotypes

\begin{tabular}{lllll}
\hline Trait & $\begin{array}{l}\text { Trial } \\
\text { mean }\end{array}$ & $\begin{array}{l}\text { Range of } \\
\text { predicted } \\
\text { means }\end{array}$ & $\sigma_{\mathrm{g}}^{2}(\mathrm{SE})$ & $\begin{array}{l}\text { Heritability } \\
\left(h^{2}\right)\end{array}$ \\
\hline RSG & 0.87 & $0.35-1.04$ & $0.0208(0.0038)$ & 0.66 \\
RRL & 0.233 & $0.080-0.563$ & $0.0092(0.0016)$ & 0.85 \\
RSL & 0.108 & $0.013-0.274$ & $0.0038(0.0006)$ & 0.78 \\
\hline
\end{tabular}


germination under salinity. It was $58-70 \%$ in genotypes SP 20666B, ICSB 401 and ICSR 90017 indicating that these were moderately sensitive. Seventeen genotypes, other than the six mentioned above, were significantly (71-83\%) less in RSG (data not shown).

Following seed germination, the ratio of root and shoot growth of the seedlings, estimated as length under salinity to that of control, was also adversely affected and varied greatly across genotypes (Table 3). Shoot growth was relatively more affected by salinity than root growth as shown by the overall means and the ranges of these two traits (Table 3). The significance pattern of the genetic correlations, while relating RSG, RRL and RSL of the seedlings with the shoot biomass ratio at 18, 25, 32 and 39 DAS, was largely the same as that of the phenotypic correlation (Table 4). Neither RSG nor RRL was genetically correlated with the shoot biomass ratio at any stage except for a significant phenotypic correlation of RSG with shoot biomass ratio at 25 DAS. However, RSL was generally correlated with the shoot biomass ratio observed at different stages with a probability level range of 0.05-0.01 (Table 4). The correlations coefficients obtained with shoot biomass under salinity instead of shoot biomass ratio were also largely of similar magnitude (data not shown).

\section{Discussion}

The main purpose of this study was to assess the range of variation for salinity tolerance of biomass production in sorghum, as a first step to future breeding efforts. We have identified genotypes that are contrasting for their relative biomass production at the early vegetative stage. The most tolerant entries included some elite Blines, such as ICSB 589, ICSB 676 and ICSB 766, that are regularly used in the crossing program for introgressing various other tolerance characteristics, and a few improved varieties, such as CSV 15, NTJ 2, ICSV 95030 and S 35, that are already cultivated in many parts of the world. Similarly, the highly sensitive entries also included B-lines (ICSB 405, ICSB 699 and ICSB 700), restorers (ICSR 93024-2, ICSR 170 and ICSR 56) and improved varieties (ICSV 90017 and ICSV 96020). We have confirmed the poor value of using an early assessment of salinity tolerance at seedling stage. We have showed some potential in the use of shoot $\mathrm{Na}$ concentration as an indirect selection criterion.

Measuring the biomass production at 39 DAS following saturation of the soil to field capacity with a $250-\mathrm{mM} \mathrm{NaCl}$ solution has provided an accurate screen for tolerance of the relative biomass production in the early vegetative stage
Table 4 Genetic and phenotypic correlations of the shoot biomass ratios (salinity/control) (SBR) observed at 18, 25, 32 and 39 days after sowing (DAS) with the relative seed germination (\%) (RSG), relative root length ratio (RRL) and the relative shoot length ratio (RSL) in 84 sorghum genotypes

\begin{tabular}{|c|c|c|c|c|c|c|}
\hline & SBR (18 DAS) & SBR (25 DAS) & SBR (32 DAS) & SBR (39 DAS) & RSG & RRL \\
\hline \multicolumn{7}{|c|}{ Genetic correlation } \\
\hline SBR (25 DAS) & $0.463 * *$ & & & & & \\
\hline SBR (32 DAS) & $0.437 * *$ & $0.676^{* * *}$ & & & & \\
\hline SBR (39 DAS) & $0.404 * *$ & $0.531 * * *$ & $0.831 * * *$ & & & \\
\hline RSG & 0.249 & 0.106 & 0.061 & -0.032 & & \\
\hline RRL & 0.117 & -0.052 & 0.051 & 0.208 & 0.194 & \\
\hline RSL & $0.341 *$ & $0.361 * *$ & $0.260^{*}$ & $0.347 * *$ & 0.211 & $0.467 * * *$ \\
\hline \multicolumn{7}{|c|}{ Phenotypic correlation } \\
\hline SBR (25 DAS) & $0.248 * * *$ & & & & & \\
\hline SBR (32 DAS) & $0.280 * * *$ & $0.409 * * *$ & & & & \\
\hline SBR (39 DAS) & $0.231 * * *$ & $0.169 *$ & $0.392 * * *$ & & & \\
\hline RSG & 0.134 & $0.152 *$ & 0.026 & -0.093 & & \\
\hline RRL & 0.057 & -0.028 & 0.017 & 0.114 & 0.143 & \\
\hline RSL & $0.186^{* *}$ & $0.222 * *$ & $0.164 *$ & $0.204 * *$ & $0.172 *$ & $0.462 * * *$ \\
\hline
\end{tabular}

$*, * *, * * *$ indicates significance at $0.05,0.01$ and 0.001 probability levels, respectively 
under saline conditions, and has revealed substantial variation among genotypes. The salt concentration $(250 \mathrm{mM} \mathrm{NaCl}$ resulting in a soil ECe of $18.1 \pm 0.19 \mathrm{dS} \mathrm{m}^{-1}$ ) chosen for screening, was similar to that in some previous studies (De La Rosa-Ibarra and Maiti 1995; Yang et al. 1990; Igartua et al. 1994; Netondo et al. 2004). However, few others have also used lower concentrations for sorghum in some other studies (ECe 10-11 dS m ${ }^{-1}$ ) (Maas 1985; Francois et al. 1984; El-Haddad and O'Leary 1994; Igartua et al. 1995). We used this salinity level to cover the salinity-affected soil levels that occur in most sorghum growing areas globally as large number of previous workers has chosen $15-20 \mathrm{dS} \mathrm{m}^{-1}$ as screening medium for screening large number of sorghum genotypes. The level of salt concentration used in the present study seemed suitable for screening this crop species as only few genotypes could reach a ratio of 0.50 at the maximum productivity stage (39 DAS) in this study under salinity.

The $\mathrm{Na}^{+}$concentration in plant shoots under saline conditions appeared to be the trait that was the most closely related to the shoot biomass ratio $(29 \%, p \leq 0.001)$. The use of shoot $\mathrm{Na}^{+}$concentration to predict the shoot biomass ratio would certainly deserve more investigation to identify an accurate screen related to the ionic relation in plant under salinity. Sorghum has been considered to be an efficient excluder of $\mathrm{Na}^{+}$from aerial plant parts, restricting $\mathrm{Na}^{+}$accumulation to its roots (Weinberg et al. 1984; Grieve and Maas 1988). Recent data show that sorghum genotypes accumulate $\mathrm{Na}^{+}$in their roots and stems but succeed in excluding most of it from their leaves (Netondo et al. 2004). So, further investigation of the localization of $\mathrm{Na}$ in plant part and its possible relation with tolerance is needed. The $\mathrm{K}^{+} / \mathrm{Na}^{+}$ and $\mathrm{Ca}^{2+} / \mathrm{Na}^{+}$ratios were also significantly and positively associated with the shoot biomass ratio, though fairly poorly. In contrast, among various characteristics that was studied only the shoot growth ratio of the seedlings and the shoot biomass ratio at early vegetative stages were related but the magnitude of this relationship was low $\left(r^{2} \leq 0.11\right)$. A germination test would, nonetheless, be useful to discard accessions that are sensitive to salinity at germination stage and thus would help in limiting the number for the actual screening. Removal of such sensitive material as well as the ones with poor seed viability are expected to decrease the error variances in experimental measurements conducted at later stages of plant growth.

For understanding the genetic control of salinity tolerance as shoot biomass ratio produced under salinity to that of control, the heritability values were estimated for this ratio. These heritability values for salinity tolerance ranged from 0.36 to 0.46 showing that the genetic differences explain a major part of the phenotypic differences. There may be a scope to further improve the screening efficiency for shoot biomass ratio and thereby the operational heritability values by sampling larger numbers of plants at one-time. In relatively more sensitive rice, the heritability values reported were low. The narrow sense $(0.198)$ and broad sense $(0.367)$ heritability values for $\mathrm{K}^{+} / \mathrm{Na}^{+}$ratio, at $12 \mathrm{dS} \mathrm{m}^{-1}$ culture medium conditions were 0.198 and 0.367 , respectively (Akbar et al. 1985).

\section{Conclusions}

Overall, it can be concluded that substantial variation in early vegetative stage salinity tolerance among sorghum genotypes was found in this study, and several relatively salinity tolerant and sensitive sorghum genotypes for biomass production were identified. The $\mathrm{Na}^{+}$exclusion from the shoot, estimated by shoot $\mathrm{Na}^{+}$content or $\mathrm{K}^{+} / \mathrm{Na}^{+}$ratio, was well-related to the ratio of shoot biomass, our proxy for salinity tolerance. Further investigation would be needed in that relation to find out a more accurate screen. Seed germination or early seedling growth responses to salinity are not useful as traits for selection of salinity tolerant genotypes as their relationship to shoot biomass ratio were not adequately close.

Acknowledgments This research was supported partly by OPEC Fund for International Development assigned to biotechnology-assisted improvement in salinity tolerance through the GT-Biotechnology of ICRISAT. The authors gratefully acknowledge the guidance on statistics provided by Dr Subhash Chandra, Principal Scientist (Biometrics 
and Bioinformatics), ICRISAT and the useful comments and suggestions given by Dr Vincent Vadez and Dr F.R. Bidinger, Consultant Physiologist, Crop Physiology to improve the manuscript.

\section{References}

Akbar M, Khush GS, HilleRisLambers D (1985) Genetics of salt tolerance in rice. In: Rice genetics. IRRI, Los Banos, Laguna, Philippines, pp 399-409

Ashraf M, McNeilly T (1987) Salinity effects on five cultivars/lines of pearl millet (Pennisetum americanum [L] Leeke). Plant Soil 103:13-19

Ayers RS, Westcott DW (1985) Water quality for agriculture. FAO Irrigation and Drainage Paper No. 29 (Rev. 1), Rome, Italy

Azhar FM, McNeilly T (1987) Variability for salt tolerance in Sorghum bicolor (L) Moench under hydroponic conditions. J Agron Crop Sci 159:269-277

Azhar FM, McNeilly T (1988) The genetic basis of variation for salt tolerance in Sorghum bicolor (L) Moench seedlings. Plant Breed 101:114-121

De La Rosa-Ibarra M, Maiti RK (1995) Biochemical mechanism in glossy sorghum lines for resistance to salinity stress. J Plant Physiol 146:515-519

El-Haddad EHM, O'Leary JW (1994) Effect of salinity and $\mathrm{K} / \mathrm{Na}$ ratio of irrigation water on growth and solute content of Atriplex amnicola and Sorghum bicolor. Irrigation Sci 14:127-133

Ellis RP, Forster BP, Waugh R, Bonar N, Handley LL, Robinson D, Gordon DC, Powell W (1997) Mapping physiological traits in barley. New Phytol 137:149-157

Epstein E (1985) Salt-tolerant crops: origins, development, and prospects of the concept. Plant Soil 89:187-192

Epstein E, Jeffries RL (1964) The genetic basis of selective ion transport in plants. Annu Rev Plant Physiol 15:169-184

Epstein E, Rains DW (1987) Advances in salt tolerance. Plant Soil 99:17-29

Flowers TJ, Koyama ML, Flowers SA, Sudhakar C, Singh KP, Yeo AR (2000) QTL: their place in engineering tolerance of rice to salinity. J Exp Bot 51:99-106

Francois LE, Maas EV (1994) Crop response and management on salt-affected soils. In: Pessarakli M (ed) Handbook of plant and crop stress. Marcel Dekker, New York, pp 149-181

Francois LE, Donovan T, Maas EV (1984) Salinity effects on seed yield, growth and germination of grain sorghum. Agron J 76:741-744

Ghassemi F, Jakerman AJ, Nix HA (1995) Salinisation of land and water resources: human causes, extent, management and case studies. CAB International, Wallingford, UK, 526 pp

Gregorio GB, Senadhira D (1993) Genetic analysis of salinity tolerance in rice (Oryza sativa L.). Theor Appl Genet 86:333-338

Grieve CM, Maas EV (1988) Betaine accumulation in saltstressed sorghum. Physiol Plant 61:167-171
Hassanein AM (1985) Salt tolerance of fifty grain sorghum genotypes at seedling stage. Ann Agric Sci (Egypt) 30:163-176

Igartua E, Gracia MP, Lasa JM (1994) Characterization and genetic control of germination-emergence responses of grain sorghum to salinity. Euphytica 75:185-193

Igartua E, Gracia MP, Lasa JM (1995) Field responses of grain sorghum to a salinity gradient. Field Crops Res 42:15-25

Iyengar ERR, Reddy MP (1994) Crop response to salt stress: sea water application and prospects. In: Pessarakli M (ed) Handbook of plant and crop stress. Marcel Dekker, New York, pp 183-203

Koyama ML, Levesley A, Koebner RMD, Flowers TJ, Yeo AR (2001) Quantitative trait loci for component physiological traits determining salt tolerance in rice. Plant Physiol 125:406-422

Krom M (1980) Spectrometric determination of ammonia: a study of modified Berthelot reaction using salicylate and dichloroisocyanurate. Analyst 105:305-316

Maas EV (1985) Crop tolerance to saline sprinkling water. Plant Soil 89:273-284

Maiti RK, de la Rosa-Ibarra M, Sandowal ND (1994) Genotypic variability in glossy sorghum lines for resistance to drought, salinity and temperature-stress at seedling stage. J Plant Physiol 143:241-244

Mano Y, Takeda K (1997) Mapping quantitative trait loci for salt tolerance at germination and the seedling stage in barley (Hordeum vulgare L.). Euphytica 94:263-272

McNeilly T (1990) Selection and breeding for salinity tolerance in crop species. A case of optimism? Acta Ecol 11:595-610

Munns R, James RA (2003) Screening methods for salinity tolerance: a case study with tetraploid wheat. Plant Soil 253:201-218

Munns R, Hare RA, James RA, Rebetzke GJ (2000) Genetic variation for improving the salt tolerance of durum wheat. Aust J Agric Res 51:69-74

Munns R, Husain S, Rivelli AR, James RA, Condon AG, Lindsay MP, Lagudah ES, Schachtman DP, Hare RA (2002) Avenues for increasing salt tolerance of crops, and the role of physiologically based selection traits. Plant Soil 247:93-105

Netondo GW, Onyango JC, Beck E (2004) Sorghum and salinity. I. Response of growth, water relations, and ion accumulation to $\mathrm{NaCl}$ salinity. Crop Sci 44:707710

Payne RW (ed) (2002) The guide to GenStat ${ }^{\circledR}$ Release 6.1. Part 2: Statistics. VSN International Ltd, Oxford, UK

Poustini K, Siosemardeh A (2004) Ion distribution in wheat cultivars in response to salinity stress. Field Crops Res 85:125-133

Sahrawat KL, Ravikumar G, Murthy KVS (2002) Sulfuric acid selenium digestion for multi-element analysis in a single plant digest. Commun Soil Sci Plant Anal 33:3757-3765

Semikhodiskii AG, Quarrie SA, Snape JW (1997) Mapping quantitative trait loci for salinity responses in 
wheat. In: Drought and plant production, proceedings of Lipenski Vir meeting, Serbia, 1996, pp 83-92

Shannon MC (1984) Breeding, selection and the genetics of salt tolerance. In: Staples RC, Toeniessen GH (eds) Salinity tolerance in plants. Wiley, New York, pp 231-254

Shannon MC (1990) Genetic approaches for developing economic salt-tolerant crops. In: Tanji KK (ed) Agricultural salinity assessment and management. American Society of Civil Engineers, New York, pp 161-185

Szabolcs I (1994) Soils and salinization. In: Pessarakali M (ed) Handbook of plant and crop stress. Marcel Dekker, New York, pp 3-11
Tanji KK (1990) Nature and extent of agricultural salinity. In: Tanji KK (ed) Agricultural salinity assessment and management. American Society of Civil Engineers, New York, pp 1-17

Taylor RM, Young EF Jr, Rivera RL (1975) Salt tolerance in cultivars of grain sorghum. Crop Sci 15:734-735

Weinberg RW, Lerner HR, Poljakoff-Mayber A (1984) Changes in growth and water-soluble solute concentrations in Sorghum bicolor stressed with sodium and potassium salts. Physiol Plant 62:472-480

Yang YW, Newton RJ, Miller FR (1990) Salinity tolerance in Sorghum. I. Whole plant response to sodium chloride in $S$. bicolor and $S$. halepense. Crop Sci 30:775-781 